\title{
Delayed neuropathy after organophosphorus insecticide (Dipterex) poisoning: a clinical, electrophysiological and nerve biopsy study
}

\author{
C VASILESCU, MARILENA ALEXIANU, A DAN \\ From the Department of Neuromuscular Diseases, Institute of Neurology and Psychiatry, Bucharest, \\ Romania
}

SUMMARY Clinical, electrophysiological and histological findings in four patients accidentally poisoned with the organophosphorus insecticide Dipterex are reported. Three to five weeks after insecticide ingestion signs of a distal sensorimotor (preponderantly motor) neuropathy occurred. The patients complained of paraesthesia in the lower limbs, and two of them of very disagreeable pricking sensation in the soles of the feet, responsive to carbamazepine. They showed distal weakness mainly of the legs, footdrop, difficult gait and muscle hypotonia. Ankle jerk was abolished while other tendon reflexes persisted. Two months or even later after poisoning, knee jerks in all the patients were very brisk and more and less accompanied by other pyramidal signs (patellar clonus, abolishment of abdominal cutaneous reflexes, Babinski's sign). Clinical, electrophysiological and nerve biopsy data revealed a "dying-back" neuropathy in our patients. Distal muscle fatigue was confirmed by failure of neuromuscular transmission on repetitive nerve stimulation.

Concurrent signs of lesions in the peripheral nervous system and central nervous system have been already described for experimental triorthocresyl phosphate (TOCP) poisoning. ${ }^{2}$ In previous works ${ }^{34}$ we reported cases showing, 2-3 months following TOCP-polluted alcohol ingestion, simultaneous peripheral and central nervous system signs of lesions, predominantly in the distal portions of the longer axons. Accordingly, a "dying-back" process appears to underlie the TOCP-neuropathy, which Cavanagh has been the first to mention. ${ }^{15}$

A recent review ${ }^{6}$ summarises all cases of delayed neuropathy after trichlorphon (Chlorphos ${ }^{7}$ or Dipterex ${ }^{34}$ ) intoxication. The present study is an attempt to supply further evidence on Dipterexinduced neuropathy and its underlying mechanism.

\section{Patients and methods}

Case 1 A 19-year-old female who ingested by chance

Address for reprint requests: Dr C Vasilescu, Department of Neuromuscular Diseases, Institute of Neurology and Psychiatry, Berceni 10, C. P. 61-80, R-75622 Bucharest, Romania.

Received 19 July 1983 and in revised form 3 November 1983

Accepted 5 November 1983 about $20 \mathrm{~g}$ active substance of Dipterex (dimethyl-2, 2, 2-trichloro-1-hydroxy-ethyl-phosphonate).

Case 2 A 22-year-old man had ingested the same amount of Dipterex concomitantly with $\mathbf{0 . 5}$ litre alcohol (brandy).

Case 3 A 32-year-old female intoxicated with about $25 \mathrm{~g}$ active substance of Dipterex.

Case 4 A 38-year-old man, poisoned following ingestion of about $20 \mathrm{~g}$ active substance of Dipterex.

Control Subjects 30 healthy subjects (mean age $41 \cdot 5$ years) without symptoms or signs of neuromuscular disease were selected for the control group.

\section{Electrophysiological techniques}

All the electrophysiological recordings were obtained by means of a Disa 1500 Digital EMG-System. For temperature measurements a Disa Biological Temperature Unit with 13 L10 Concentric Needle Electrode with Temperature Sensor was used.

Electromyography (EMG) was performed with concentric bipolar needle electrodes (Disa 15K059) - at rest and on maximal contraction-in the tibialis anterior, abductor pollicis brevis and abductor digiti minimi muscles.

Conduction velocity The motor conduction velocity (MCV) and sensory conduction velocity (SCV) were measured in the peroneal, median and ulner nerves. Technical details are given in a previous paper. ${ }^{4}$

Nerve excitability threshold Measurements of the motor fibre threshold were made both distally and proximally, namely at wrist and elbow, in the median and ulnar nerves. 
Table 1 Clinical, electrophysiological and nerve biopsy findings in four patients with delayed neuropathy after organophosphorous insecticide (Dipterex) poisoning

\begin{tabular}{|c|c|c|c|c|c|c|}
\hline \multirow[t]{2}{*}{ Symptom or sign } & \multirow[t]{2}{*}{ Peripheral neuropathy } & \multirow[t]{2}{*}{ Pyramidal signs } & \multicolumn{4}{|c|}{ Patient } \\
\hline & & & 1 & 2 & 3 & 4 \\
\hline $\begin{array}{l}\text { Clinical } \\
\text { Onset of neuropathy } \\
\text { Pins and needles on the soles and plantar side of toes } \\
\text { Sensory loss } \\
\text { Ankle jerk } \\
\text { Knee jerk } \\
\text { Patellar clonus } \\
\text { Abolishment of abdominal cutaneous reflexes } \\
\text { Footdrop } \\
\text { Moderate wasting (lower limbs, distally) } \\
\text { Raynaud's phenomenon (lower limbs, distally) } \\
\text { Weakness (upper limbs, distally) }\end{array}$ & $\begin{array}{l}3-5 \text { weeks } \\
2-3 \text { weeks } \\
0 \\
\text { absent } \\
0 \\
0 \\
0 \\
+ \\
+ \\
+ \\
+\end{array}$ & $\begin{array}{l}\text { over } 2 \text { months } \\
0 \\
0 \\
0 \\
\text { brisk } \\
+ \\
+ \\
0 \\
0 \\
0 \\
0\end{array}$ & $\begin{array}{l}+ \\
+ \\
0 \\
+ \\
+ \\
+ \\
+ \\
+ \\
+ \\
+ \\
+\end{array}$ & $\begin{array}{l}+ \\
+ \\
0 \\
+ \\
+ \\
+ \\
+ \\
+ \\
+ \\
+ \\
+\end{array}$ & $\begin{array}{l}+ \\
+ \\
0 \\
+ \\
+ \\
0 \\
+1- \\
+ \\
+1- \\
+1- \\
+\end{array}$ & $\begin{array}{l}+ \\
+ \\
0 \\
+ \\
+ \\
+ \\
+1- \\
+ \\
+1- \\
+1- \\
+\end{array}$ \\
\hline $\begin{array}{l}\text { Electromyography } \\
\text { Severe denervation (lower limbs, distally) } \\
\text { Partial denervation (upper limbs, distally) } \\
\text { Motor conduction velocity } \\
\text { Sensory conduction velocity } \\
\text { Amplitude of evoked muscle action potentials } \\
\text { Amplitude of sensory evoked potentials } \\
\text { Nerve excitability threshold (median, at wrist) }\end{array}$ & $\begin{array}{l}+ \\
+ \\
+1- \\
+1- \\
+ \\
+ \\
\text { mean threshold: } \\
168 \% \mathrm{x}\end{array}$ & $\begin{array}{l}0 \\
0 \\
0 \\
0 \\
0 \\
0 \\
0\end{array}$ & $\begin{array}{l}+ \\
+ \\
\mathbf{N} \\
\mathbf{N} \\
\mathrm{MD} \\
\mathrm{MD} \\
+\end{array}$ & $\begin{array}{l}+ \\
+ \\
\text { N/MS } \\
\text { MS/N } \\
\text { MD } \\
\text { MD } \\
+\end{array}$ & $\begin{array}{l}+ \\
+ \\
\mathbf{N} \\
\mathbf{N} \\
\mathrm{MD} \\
\mathrm{MD} \\
+\end{array}$ & $\begin{array}{l}+ \\
+ \\
\mathbf{N} \\
\mathbf{N} \\
\mathrm{MD} \\
\mathrm{MD} \\
+\end{array}$ \\
\hline Nerve excitability threshold (ulnar, at wrist) & $\begin{array}{l}\text { mean threshold: } \\
144 \%\end{array}$ & 0 & + & + & + & + \\
\hline Neuromuscular transmission failure & + & 0 & + & + & + & + \\
\hline $\begin{array}{l}\text { Sural nerve biopsy } \\
\text { Axonal degeneration } \\
\text { Loss of myelinated axons } \\
\text { Segmental demyelination }\end{array}$ & $\begin{array}{l}+ \\
+ \\
+1-\end{array}$ & $\begin{array}{l}0 \\
0 \\
0\end{array}$ & $\begin{array}{l}\text { ND } \\
\text { ND } \\
\text { ND }\end{array}$ & $\begin{array}{l}+ \\
+ \\
+1-\end{array}$ & $\begin{array}{l}\text { ND } \\
\text { ND } \\
\text { ND }\end{array}$ & $\begin{array}{l}\text { ND } \\
\text { ND } \\
\text { ND }\end{array}$ \\
\hline $\begin{array}{l}\text { Muscle biopsy } \\
\text { Denervation signs }\end{array}$ & + & 0 & ND & + & ND & ND \\
\hline
\end{tabular}

$\mathbf{N}=$ Normal

MS = Mild slowing

MD = Marked decrease

ND $=$ Not done

$\mathrm{x}=$ Increased vs control values

Further technical details may be found elsewhere. 9

Neuromuscular transmission For stimulation surface electrodes (Disa 13K62) were employed, using a square wave of $0 \cdot 1 \mathrm{~ms}$ duration and supramaximal intensity (150\% higher than the intensity inducing a maximal electrical response). We applied succesive stimulus trains $(1.2 \mathrm{~s}$ in duration) at 3 min stimulus-free intervals. Evoked muscle action potentials (EMAPs) in the abductor digiti minimi, on stimulation of the ulnar nerve at wrist, were recorded under isometric conditions by surface electrodes (Disa 13K60) with belly-tendon leads.

\section{Histological techniques}

Gastrocnemius muscle biopsy For light microscopy transverse frozen sections were stained with haematoxylineosin; van Gieson; modified Gomori's trichrome and treated for myofibrillar ATPase at $\mathrm{pH} 9 \cdot 4$, ATPase after acid preincubation at $\mathrm{pH} 4 \cdot 63$ and $4 \cdot 35$. Vestopal-embedded semithin sections were stained with toluidine blue for light microscopy and ultrathin sections, with uranyl acetate and lead citrate for electron microscopy.

Sural nerve biopsy In the histological, histochemical and ultrastructural studies Dyck's methods were used. ${ }^{10} 11$

\section{Results}

\section{CLINICAL FEATURES}

Case 1 Dipterex ingestion resulted, after $30 \mathrm{~min}$, in abdominal colic, dizziness, sight disturbances, diarrhoea, vomiting, fall of arterial blood pressure. The patient was comatose for one hour. In spite of the tranquilisers administered, she could not sleep for four nights and complained of visual hallucinations. Two weeks following her intoxication she had burning, pin and needle sensations in the soles and plantar side of the toes, which rendered walking impossible. Carbamazepine administration (600 $\mathrm{mg} /$ day) diminished these subjective signs which finally disappeared (the patient was able to walk). After three weeks from Dipterex poisoning, footdrop with difficult gait occurred; the patient could not walk on toes and heels. The ankle jerk was abolished while the knee jerk preserved. Some time later we observed a discrete atrophy of the peronei and of small foot muscles. Three months following 
intoxication very brisk knee jerks, patellar clonus, abolishment of abdominal cutaneous reflexes and Babinski's sign on the right side, occurred in addition. Intensive physiotherapy and neuromotor rehabilitation led to improvement of the peripheral neuropathy signs and the peroneal nerve became again excitable (one year and a half after poisoning). Concomitantly, the distal weakness in the upper limbs disappeared, and in the lower ones markedly diminished. Clinical and electrophysiological data are listed in table 1.

Case 2 After Dipterex and alcohol ingestion, the patient was comatose for 5 days. Treatment with atropine, plasma, etc. in an emergency unit induced acetyl choline esterase increase from $0.10 \mathrm{u} / \mathrm{ml}$ to $4.8 \mathrm{u} / \mathrm{ml}$. Two weeks after intoxication pin and needle sensations in the soles and plantar side of toes occurred, which disappeared with the administering of $600 \mathrm{mg} /$ day carbamazepine. One week later neuropathy became apparent, the patient being unable to walk on toes and heels. Achille's reflex was abolished while the knee jerk was present. Six months after his poisoning the patient showed a distal motor neuropathy (footdrop, disturbed orthostatism, difficult gait, distal muscle atrophy predominantly of the peronei and small foot muscles, abolished ankle jerks) and pyramidal signs in the proximal segments (very brisk knee jerks, patellar clonus, abolished abdominal cutaneous reflexes, mild spasticity in the thigh muscles). Raynaud's phenomenon also occurred in the lower limbs (distally) with increased distal sweating both in the lower and upper limbs. Following one year and a half of intensive physiotherapy and neuromotor rehabilitation, the signs of peripheral neuropathy subsided partially: the distal weakness had vanished in the upper limbs and had substantially diminished in the lower ones. Raynaud's phenomenon had disappeared, but distal sweating in the lower and upper limbs persisted.

Case 3 Dipterex poisoning made the patient comatose for four days. Two weeks later paraesthesia of the lower limbs, pin and needle sensations in the soles occurred. After another two weeks there were signs of peripheral neuropathy, namely difficult gait, footdrop, abolished ankle jerks, distal weakness in the upper and lower limbs and mild Raynaud's phenomenon in the lower limbs (distally). Six months following intoxication the patient showed in addition pyramidal signs: brisk knee jerks and diminished abdominal cutaneous reflexes. The distal weakness in the upper limbs decreased.

Case 4 One week after poisoning the patient was admitted to hospital for acute gastritis induced by Dipterex. At five weeks following his intoxication peripheral neuropathy (lower limbs) occurred, he was again hospitalised. The patient complained of pain in the calves. Neurological examination showed distal weakness, difficult gait. He was unable to walk on toes and heels. The ankle jerk was abolished, while other tendon reflexes persisted. After two months from Dipterex ingestion he showed brisk knee jerks and patellar clonus. Of the abdominal cutaneous reflexes only the upper ones were present.

\section{ELECTROPHYSIOLOGICAL FINDINGS}

Electromyography revealed marked distal denervation of the lower limb muscles and partial distal denervation of the upper ones in all patients.

Nerve conduction The MCV and SCV values are listed in table 2. Both MCV and distal latency had normal values (only the peroneal nerve was unexcitable). The SCV values were also normal (excepting in case 2 where SCV slightly slowed in the digital segments of the median and ulnar nerves, two months after intoxication; four months later MCV and SCV also returned to normal ranges, except the peroneal nerve). Amplitude of EMAPs in the distal muscles and of sensory evoked potentials (SEPs) at wrist, following stimulation of digital fibres, was markedly decreased (more than half of the normal values).

Nerve excitability threshold We found the peroneal nerve unexcitable in all patients. In Case 2, three weeks after poisoning, the MCV was $42 \mathrm{~m} / \mathrm{s}$ while EMAP amplitude only $750 \mu \mathrm{V}$. In Case 1 , following partial regeneration during one year and a half, the peroneal nerve showed a MCV of $37.5 \mathrm{~m} / \mathrm{s}$ and EMAP amplitude of merely $50 \mu \mathrm{V}$. A significant distal hypoexcitability of the median and ulnar nerves at wrist occurred (table 1).

Neuromuscular transmission A decrement (over $10 \%$ ) of EMAPs in abductor digiti minimi on ulnar nerve stimulation at wrist was found in all patients (figs 1 and 2). There were also noted transient posttetanic facilitation and postfacilitation exhaustion.

\section{HISTOLOGICAL FINDINGS}

Gastrocnemius muscle Light microscopy disclosed neurogenic atrophy changes (isolated angular fibres, small group atrophy) and reinnervation (moderate fibre type grouping). Electron microscopy showed areas of myofibril disorganisation namely from discrete alterations in Z-band to severe myofibrillar destruction.

Sural nerve biopsy showed a slight decrease in the density of myelinated fibres (D: $8,500 / \mathrm{mm}^{2}$ ), particularly of the larger ones (histogram of nerve fibres, fig 3). Numerous small myelinated axons observed and certain axons having disproportionately thin myelin sheath (remyelinated fibres) were 
Table 2 Electrophysiological data in four patients with delayed neuropathy after organophosphorus insecticide (Dipterex) poisoning

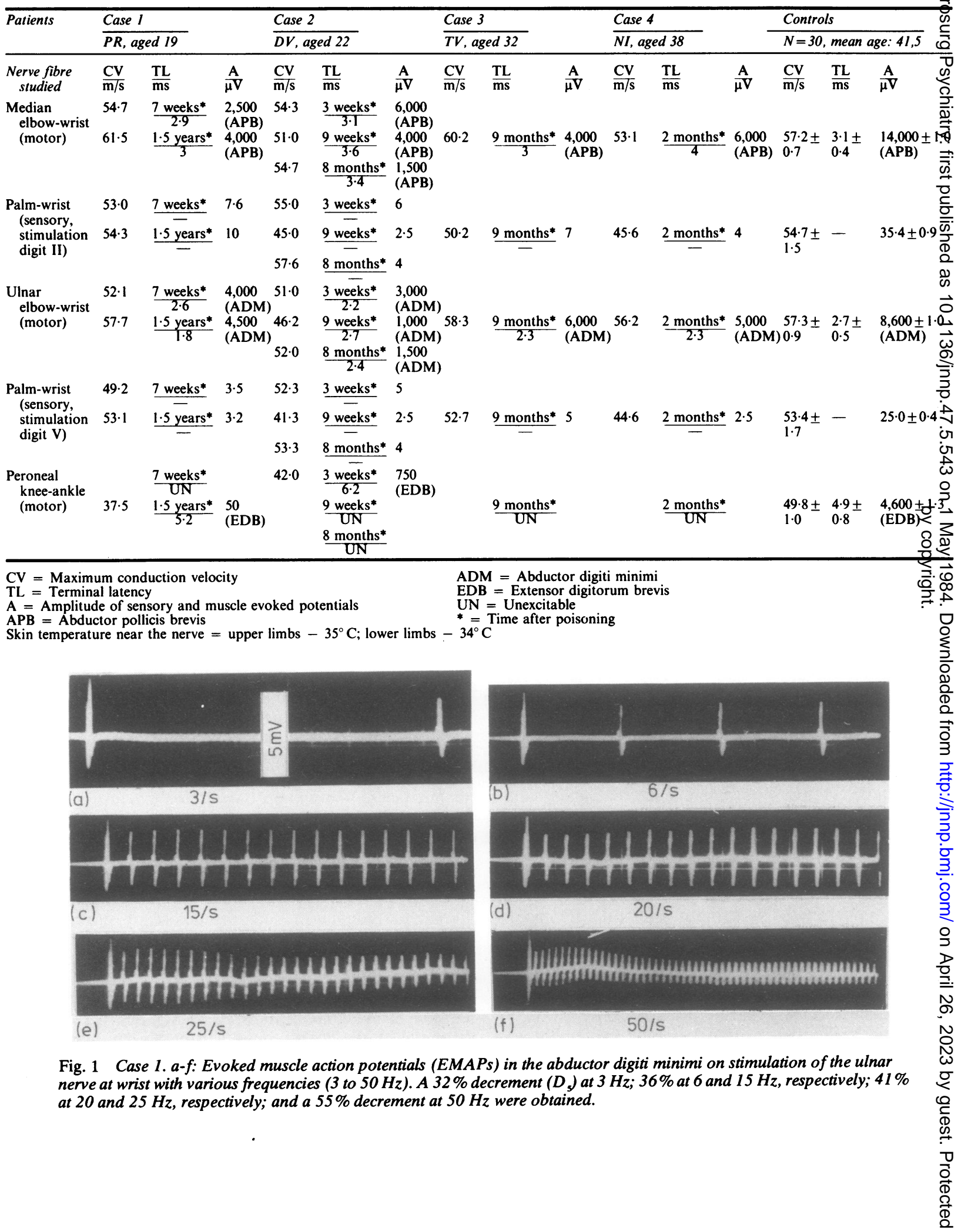




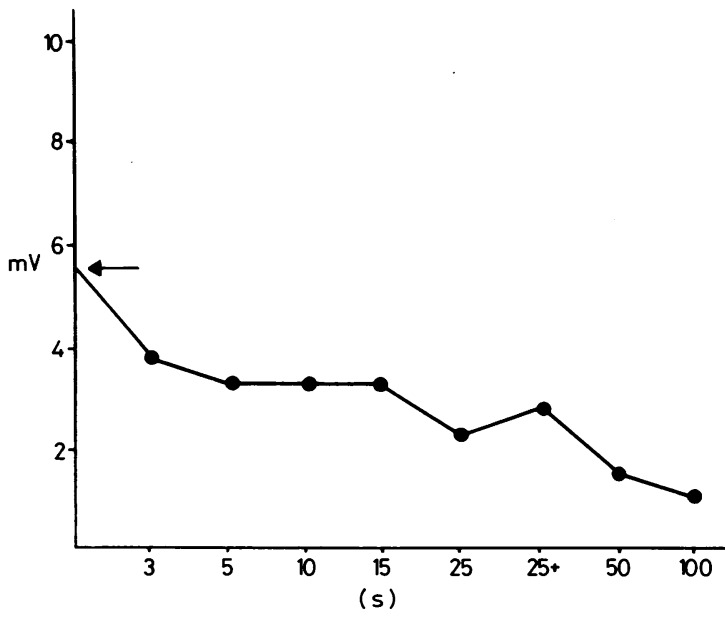

Fig. 2 Case 1. Diagram showing the peak-to-peak amplitude evolution of EMAPs in the last potential of the train in the abductor digiti minimi on stimulation of the ulnar nerve at wrist as a function of the stimulation frequency. $25^{+}$: amplitude of the EMAP in the last train (15th) in a continuous series of trains ( $1.2 \mathrm{~s}$ duration, each) of repetitive stimulation ( $25 \mathrm{~Hz}$ ). Arrow: initial EMAP amplitude.

indicative of axonal regeneration. Electron microscopy revealed hyperactive Schwann cells.

Teasing data: $50 \%$ normal myelinated fibres, $34 \%$ fibres with total demyelination all along their length, $10 \%$ regenerated fibres re-myelinated all along their length, $6 \%$ fibres with segmental demyelination.

\section{Discussion}

Our four patients who had accidentally ingested Dipterex showed, after a delayed period of 3 to 5

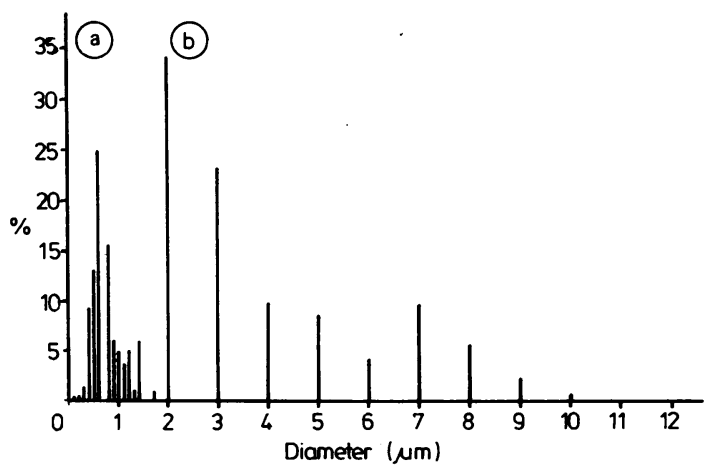

Fig. 3 Case 2. 5 weeks after ingestion of Dipterex. Histogram of the sural nerve fibres. a: Unmyelinated fibres. b: Myelinated fibres. weeks, clinical signs of distal motor peripheral neuropathy, chiefly in the lower limbs. At the onset of neuropathy the ankle jerk was abolished while other tendon reflexes persisted. Two months and even later following Dipterex ingestion, we found in the proximal segments of the lower limbs moderate pyramidal signs. As in our previously described cases of delayed TOCP-induced neuropathy, ${ }^{34}$ these pyramidal signs were probably present also in the distal segments of the lower limbs, but were masked by the peripheral neuropathy. Clinical, electrophysiological and nerve biopsy findings are compatible with a mixed distal sensorimotor (predominantly motor) neuropathy. According to the above evidence, Dipterex damaged preponderantly the longer and larger axons and more severely their distal portions. The patients investigated showed signs of both peripheral and central nervous system lesions in the distal portion of the longer axons, the peripheral lesions in particular resembling to those in the predominantly neuropathic form of TOCPinduced neuropathy. ${ }^{4}$

Electrophysiological findings as well as light and electron microscopy of sural nerve suggest that an axonal degeneration with secondary demyelination and remyelination underlie the Dipterex-induced neuropathy. In the present cases as in those of TOCP-neuropathy, ${ }^{4}$ the secondary demyelination and remyelination are supposed to occur in fibres which had already undergone degeneration followed by regeneration, as Dyck et al ${ }^{11}$ showed for uraemic neuropathy.

The signs of both peripheral and central lesions observed by us were generally similar-excepting some differences - to those reported by Cavanagh ${ }^{15}$ and Prineas ${ }^{2}$ who proved concurrent peripheral and central degeneration in experimental "dying-back" disease due to TOCP. Similar findings were also described for $\mathbf{n}$-Hexan neuropathy by Spencer and Schaumburg ${ }^{12}$ who suggested naming this type of disease "central-peripheral distal axonopathy".

In one of our patients we found that concomitant alcohol ingestion enhanced the Dipterex toxic effect, as Vernik has already reported. ${ }^{8}$

Distal muscle fatigue was confirmed by decrement of EMAPs (over $10 \%$ ) on repetitive nerve stimulation, transient post-tetanic facilitation and postfacilitation exhaustion. A myasthenia-like syndrome was probably induced by Dipterex action in the presynaptic zone of motor axons, as in other cases of Dipterex or Divipan (Dichlorvos) neuropathies ${ }^{4}$ or of carbon disulphide polyneuropathy. ${ }^{9}$

In spite of normal MCV and terminal latency values, the nerve excitability threshold showed a distal motor hypoexcitability; consequently, it may be considered a significant-electrophysiological mean 
for early detection of Dipterex-induced neuropathy, as well as of other distal axonopathies. ${ }^{49}$

Increased sweating mainly in the lower limbs (distally) and presence of Raynaud's phenomenon equally distally in the lower limbs might be the result of an autonomic disturbance similar to that described in acrylamide neuropathy. ${ }^{13} 14$

The clinical features (distal motor peripheral neuropathy and mild pyramidal signs in the proximal segments) together with electrophysiological findings suggest a "dying-back" (distal axonopathy) process underlying Dipterex-induced neuropathy, as has already been mentioned for other toxic neuropathies ${ }^{1-591215-17}$ or neuropathies of various aetiologies. ${ }^{18} 19$ This viewpoint is confirmed by our nerve biopsy findings which show a distal axonal degeneration.

Following treatment of one year and a half after Dipterex intoxication, both peripheral and central lesion signs diminished: walking was very much improved, but some residual signs of distal motor peripheral neuropathy in the lower limbs (moderate distal muscle atrophy, mild distal weakness, abolishment of ankle jerks) and only one minor CNS lesion sign (brisk knee jerk) persisted. In contrast the signs of very severe residual lesions (chiefly in CNS), found 13 years after TOCP-polluted alcohol ingestion, showed a clinical picture resembling an amyotrophic lateral sclerosis syndrome in the lower $\operatorname{limbs}^{4}$ or a spinal cord syndrome rather than a neuritis. ${ }^{20}$

\section{References}

' Cavanagh JB. The toxic effects of tri-ortho-cresyl phosphate on the nervous system. J Neurol Neurosurg Psychiatry 1954;17:163-72.

${ }^{2}$ Prineas J. The pathogenesis of dying-back polyneuropathies. I. An ultrastructural study of experimental tri-ortho-cresyl phosphate intoxication in the cat. J Neuropathol Exp Neurol 1969;28:57197.

${ }^{3}$ Vasilescu C. Motor nerve conduction velocity and electromyogram in tri-ortho-cresyl phosphate poisoning. Rev Roum Neurol 1972;9:345-50.

${ }^{4}$ Vasilescu C, Florescu A. Clinical and electrophysiological study of neuropathy after organophosphorus com- pounds poisoning. Arch Toxicol 1980;43:305-15.

5 Cavanagh JB. The significance of the "dying-back" process in experimental and human neurological disease. Int Rev Exp Biol 1964;3:219-67.

- Johnson MK. Delayed neurotoxicity-do trichlorphon and/or dichlorvos cause delayed neuropathy in man or in test animals? Acta Pharmacol Toxicol 1981;94:Suppl. 5, 87-98.

${ }^{7}$ Hierons R, Johnson MK. Clinical and toxicological investigations of a case of delayed neuropathy in man after acute poisoning by an organophosphorus pesticide. Arch Toxicol 1978;40:279-84.

${ }^{8}$ Vernik AY. Polyneuritis from chlorophos. (Russian). Sov Med 1971;34:44-5.

9 Vasilescu C, Florescu A. Clinical and electrophysiological studies of carbon disulphide polyneuropathy. $J$ Neurol 1980;224:59-70.

${ }^{10}$ Dyck PJ. Pathologic alteration of the peripheral nervous system of man. In: Dyck PJ, Thomas PK, Lambert EH, eds. Peripheral Neuropathy 1975; Philadelphia:Saunders, Vol.1;1975:296-336.

' Dyck PJ, Johnson WJ, Lambert EH, O'Brien PC. Segmental demyelination secondary to axonal degeneration in uremic neuropathy. Mayo Clin Proc 1971;46:400-31.

${ }^{12}$ Spencer PS, Schaumburg HH. Central-peripheral distal axonopathy: the pathology of dying-back polyneuropathies. Prog Neuropathol 1976;3:253-96.

13 Auld RB, Bedwell SF. Peripheral neuropathy with sympathetic overactivity from industrial contact with acrylamide. Can Med Assoc J 1967;96:652-4.

${ }^{14}$ Garland TO, Patterson MWH. Six cases of acrylamide poisoning. Br Med J 1967;4:134-8.

${ }^{15}$ Prineas J. The pathogenesis of dying-back polyneuropathies. II. An ultrastructural study of experimental acrylamide intoxication in the cat. $J$ Neuropathol Exp Neurol 1969;28:598-621.

${ }^{16}$ Schoental R, Cavanagh JB. Mechanisms involved in the dying-back process: an hypothesis implicating coenzymes. Neuropathol Appl Neurobiol 1977;3:145-58.

${ }^{17}$ Senanayake N, Johnson MK. Acute polyneuropathy after poisoning by a new organophosphorus insecticide. N Engl J Med 1982;306:155-7.

${ }^{18}$ Harding AE, Muller DPR, Thomas PK, Willison HJ. Spinocerebellar degeneration secondary to chronic intestinal malabsorption: a vitamin E deficiency syndrome. Ann Neurol 1982;12:419-24.

19 Thomas PK, Selective vulnerability of the centrifugal and centripetal axons of primary sensory neurons. Muscle Nerve 1982;5:S117-21.

${ }^{20}$ Morgan JB, Penovich P. Jamaica ginger paralysis. Arch Neurol 1978;35:530-2. 